\title{
A Comparative Efficiency Study of Two Adsorbent Materials to Remove Eosin Y Dye from Aqueous Solutions
}

\author{
Ali K. Al-Muttairi ${ }^{*}$ \\ Sama A. Mustafa ${ }^{2}$ \\ Jasim M. Salman ${ }^{3}$
}

Received 22/5/2018, Accepted 14/10/2018, Published 9/12/2018

c.)

\begin{abstract}
:
This study was done to find a cheap, available and ecofriendly materials that can remove eosin y dye from aqueous solutions by adsorption in this study, two adsorbent materials were used, the shells of fresh water clam (Cabicula fluminea) and walnut shells. To make a comparison between the two adsorbents, five experiments were conducted. First, the effects of the contact time, here the nut shell removed the dye quickly, while the $C$. flumina need more contact time to remove the dye. Second, the effects of adsorbent weight were examined. The nut shell was very promising and for all used adsorbent weight, the R\% ranged from 94.87 to 99.29 . However $C$. fluminea was less effective in removing the dye with $\mathrm{R} \%$ ranged from 47.59 to 55.39. The third experiment was initial dye concentration. The $C$. fluminea showed very low ability to remove eosin y, while the nut shell was more effective in removing the dye with R\% up to 97.36 and an inverse correlation between the increase of initial dye concentration and $\mathrm{R} \%$. The fourth experiment was the effect of $\mathrm{pH}$ value of the solution and the adsorbent particles size. The results show that fine particles were more effective than granular particles. Throughout the whole study, the walnut shell was very promising in removing the dye, while the $C$. fluminea shell was much less effective than the walnut shell.
\end{abstract}

Keywords: Adsorption, Pollution, Eosin dye, Clam shell, Walnut.

\section{Introduction:}

In general, water treatment can be condensed into three major processes: physical treatment, specifically filtration and adsorption, chemical treatment, and the third type is energy intensive treatment (1). One of the most interesting applications adsorption is to get rid of dyes from wastewater by using a different types of adsorbents such as activated carbon, fly ash, and clay (2).

Dyes are used in different types of manufacturing and they are used for coloring various products. It is known that many dyes are artificial aromatic compounds, and the release of these dyes to the aquatic system raises concerns from an aesthetic and toxilogical point of view, primarily due to the fact that they affect the value of water as well as the aquatic organisms (3). Eosin Y dye is an acidic, hetero cyclic dye containing bromine atoms. It is used in many fields such as the leather industry, ink and fluorescent pigment (4).

\footnotetext{
${ }^{\mathrm{T}}$ Environmental Research and Studies Center, University of Babylon, Babylon, Iraq.

${ }^{2}$ Environmental Health Dep., College of Ecology, AlQasim Green University, Babylon, Iraq.

${ }^{3}$ Department of Biology, College of Science, University of Babylon, Babylon, Iraq

*Corresponding author: allmankind10@gmail.com
}

The walnut (Juglans regia L.) is a big deciduous tree that can be as tall as 25-35 meters and live to 100-200 years. The fruits of this tree mature throughout the summer and have the shape of rounded nuts with a radius up to $3 \mathrm{~cm}$ and weight up to $18 \mathrm{gm}(5)$.

Both trees and dry fruit have been used for cosmetic and pharmaceutical use and it is rich with antioxidants (6).

Cabicula fluminea, which also called Asian clam, is an invasive snail found in fresh water (river and lake) with a short life span. It is a bivalve with a globular shell which has a brown color and lives in the sediments $(7,8)$.

Many studies have been conducted using adsorption to remove dyes from aqueous solutions $(9,10,11)$. This study is has been carried out to find the best adsorbent to get-red of Eosin Y dye.

\section{Materials and Methods (12, 13) \\ Preparation of the solution}

A stock solution with $20 \mathrm{mg} / \mathrm{L}$ concentration of Eosin Y dye was prepared by dissolving $0.02 \mathrm{gm}$ of powdered dye in one liter of D.W., and then used in the following experiments. 


\section{Preparation of the adsorbent}

Two types of adsorbent were used in this study, the first one was walnut shell. The dried walnuts were activated by sucking it in $\mathrm{H}_{3} \mathrm{PO}_{4}$ $(10 \%)$ for one hour and then dried in the oven. It was cooled and ground to a powder by using an electrical grinder (First Macina / China). The second adsorbent was $C$. fluminea shell, which was prepared similar to the walnuts.

\section{The experiments}

Five experiments were performed to observe the effectiveness of the adsorbents and to compare the two. The first experiment was to test the effectiveness of the contact time on the adsorption of Eosin Y. A series of time (10, 20, 30, 40, 50, 60 minutes) was used, with initial dye concentration of $20 \mathrm{mg} / \mathrm{L}$ and the sample volume of $50 \mathrm{ml}$. The adsorbent weight was $1.2 \mathrm{gm}$ and $0.9 \mathrm{gm}$ for $C$. fluminea shell and walnut shell respectively.

The second experiment was done to find the effect of adsorbent weight on the adsorption process. A series of adsorbent weights were used $(0.4,0.8,1.2,1.6$ and $2 \mathrm{gm})$ for $C$. fluminea shell and $(0.3,0.6,0.9,1.2$ and $1.5 \mathrm{gm})$ walnut shell. The time contact was 10 minutes for $C$. fluminea shell and 60 minutes for the walnut shell with aninitial dye concentration of $20 \mathrm{mg} / \mathrm{L}$ and asample volume of $50 \mathrm{ml}$.

The third experiment was prepared to find out the relationship between adsorption and initial dye concentration. A series of initial dye concentration was used $(5,10,15,20$ and $25 \mathrm{mg} / \mathrm{L})$ for $C$.fluminea shell and (10, 20, 30, 40 and 50mg $\mathrm{mg} / \mathrm{L})$ for walnut shell, with adsorbent weight 1.2 and $0.9 \mathrm{gm}$ for C. fluminea and walnut shell respectively. Contact time was 10 minutes, adsorbent weight 1.2 $\mathrm{gm}$, volume sample was $50 \mathrm{ml}$ for $C$. fluminea shell. The contact time was 60 minutes, adsorbent weight was $0.9 \mathrm{gm}$, volume of sample was $50 \mathrm{ml}$ for the walnut shell.

The fourth experiment was carried out to find the effects of $\mathrm{pH}$ of the solution on the adsorption of eosin Y. Three types of medium was used; acidic $(\mathrm{pH}=3)$, neutral $(\mathrm{pH}=7)$ and alkaline $(\mathrm{pH}=9)$. The contact time was 10, 60 minutes for $C$. fluminea and walnut shell respectively. The adsorbent weight was $1.2,0.9 \mathrm{gm}$ for $C$. fluminea and walnut shell and the initial dye concentration was $20 \mathrm{mg} / \mathrm{L}$ and the sample volume was $50 \mathrm{ml}$.

The fifth experiment was done to find the effect of the adsorbent particle size. Two type were used; granular and powder, with initial dye concentration $20 \mathrm{mg} / \mathrm{L}$, adsorbent weight $0.9 \mathrm{gm}$, contact time of 60 minutes and sample volume of $50 \mathrm{ml}$ for walnut shell.

\section{Measurements}

All the samples were kept in the shaker for each selected contact time and after that they were transferred to centrifuge for 10 minutes. Then we used only the supernatant, which then was measured by using the spectrophotometer at $\lambda \max =517 \mathrm{~nm}$ (14).

\section{Results and Discussions:}

In this work, we searched for new materials that can be cheap, available and ecofriendly for adopting eosin y. In this study a comparison was done between $C$. fluminea and walnut shells.

The first experiment was performed to determine the best contact time for adsorption. The results show that generally the nut shell was more efficient in removing eosin y than $C$. fluminea shell. The nut shell reached high R\% quickly and there was a direct correlation between the increase in contact time and the increase in $\mathrm{R} \%$. The results agree with the finding of (15), while for the $C$. fluminea shell was wobbling it reach the highest R\% after 60 minutes, which was similar to the results of (16). Generally the $C$. fluminea showed very low ability to remove eosin y and the nut shell was more effective than $C$. fluminea shell. In Fig. 1, the difference between the two adsorbent can be seen, potentially due to the differentiation between their availability of surface area for the adsorption and the affinity between the dye particles and the adsorbent.

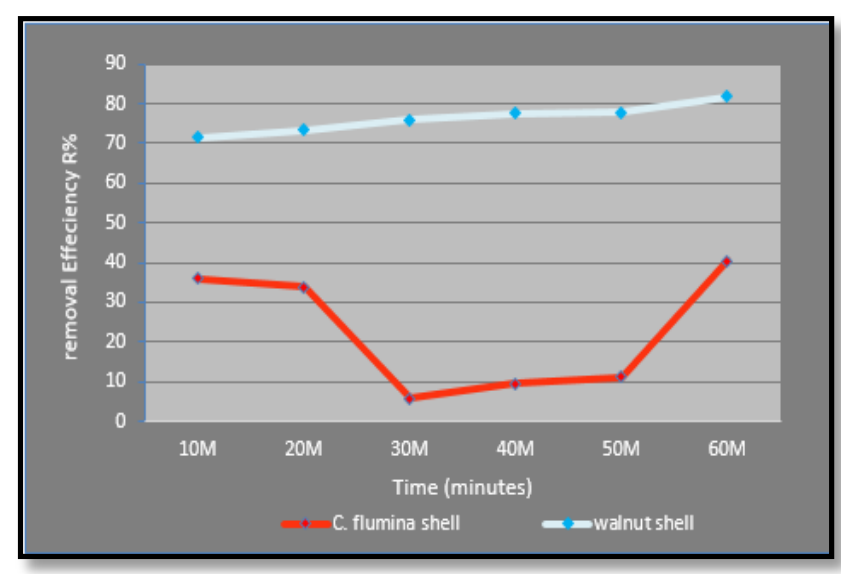

Figure 1. The effects of the contact time on the adsorption process

After determining the best contact time for adsorption, the second experiment was done to determine the best adsorbent weight. The results show that the nut shell was very promising at all weights, with $\mathrm{R} \%$ ranged from 94.87 to 99.29 . The results are analogous to the results found by (17), while the $C$. fluminea was less effective in removing the dye with $\mathrm{R} \%$ ranged from 47.59 to 55.39, as shown in Table 1 and Fig 2. It is worth mentioning that we used different adsorbent weights 
because the nut shell gave a very high $\mathrm{R} \%$ at low weight and vice versa for $C$. fluminea.

Table 1. The effects of adsorbent weight on the adsorption process

\begin{tabular}{cccc}
\hline \multicolumn{2}{c}{ C.fluminea } & \multicolumn{2}{c}{ Nut shell } \\
\hline $\begin{array}{c}\text { Adsorbent } \\
\text { weight }\end{array}$ & $\mathrm{R} \%$ & $\begin{array}{c}\text { Adsorbent } \\
\text { weight }\end{array}$ & $\mathrm{R} \%$ \\
0.4 & 55.05 & 0.3 & 97.93 \\
0.8 & 52.80 & 0.6 & 96.52 \\
1.2 & 55.39 & 0.9 & 94.87 \\
1.6 & 47.59 & 1.2 & 99.29 \\
2 & 49.51 & 1.5 & 95.22 \\
\hline
\end{tabular}

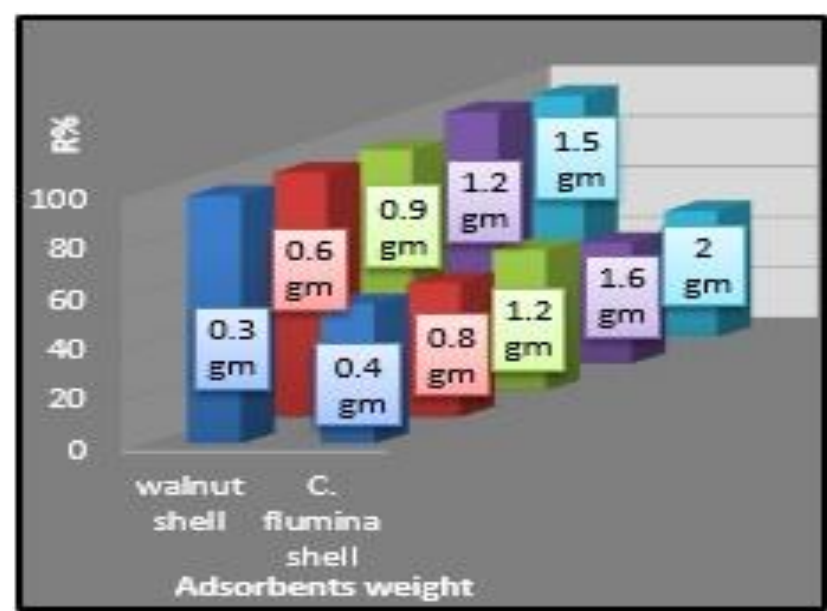

Figure 2. Shows effects of the adsorbent weight on the adsorption of the Eosin $\mathrm{Y}$ dye

The third experiment was completed to find the effects of the initial dye concentration on the adsorption process. For $C$. fluminea shell, there was an inverse correlation between the increase of initial dye concentration and $\mathrm{R} \%$, which can be explain by the fact that at the lower concentration the surface area available for adsorption is more than the available dye particles in the solution and vice versa (18). The C. fluminea show very low ability to remove eosin $\mathrm{y}$, while the nut shell was more effective in removing the dye with $\mathrm{R} \%$ up to 97.36 . There was an inverse correlation between the increase of initial dye concentration and $\mathrm{R} \%$, as illustrated in Table 3 and Fig. 3.

Table 2. The effects of the initial dye concentration on the adsorption process.

\begin{tabular}{cccc}
\hline \multicolumn{2}{c}{ C. flumina } & \multicolumn{3}{c}{ Nut Shell } \\
\hline $\begin{array}{c}\text { Initial dye } \\
\begin{array}{c}\text { Concentration } \\
(\mathrm{mg} / \mathrm{L})\end{array}\end{array}$ & $\mathrm{R} \%$ & $\begin{array}{c}\text { Initial dye } \\
\text { Concentration } \\
(\mathrm{mg} / \mathrm{L})\end{array}$ & $\mathrm{R} \%$ \\
5 & 27.93 & 10 & 90.15 \\
10 & 26.98 & 20 & 96.17 \\
15 & 24.13 & 30 & 97.36 \\
20 & 10.87 & 40 & 95.01 \\
25 & 15.37 & 50 & 81.13 \\
\hline
\end{tabular}

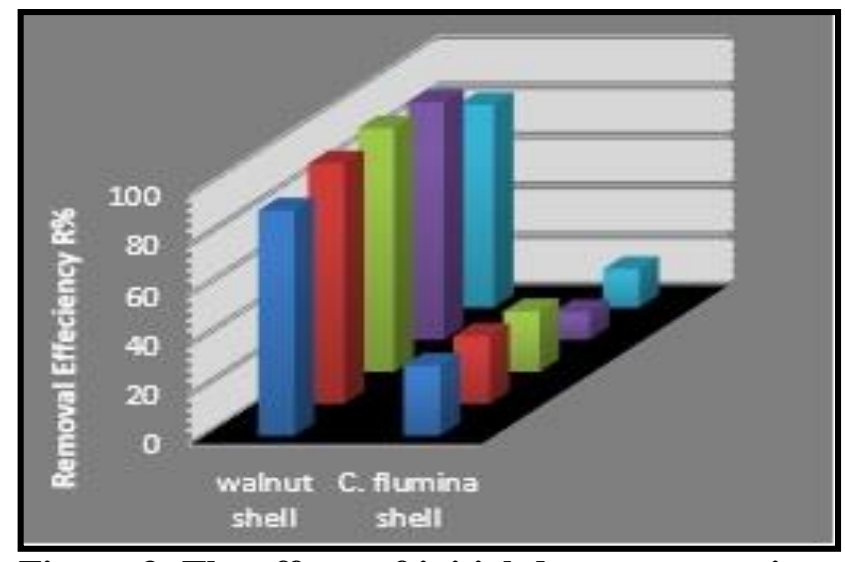

Figure 3. The effects of initial dye concentration on the adsorption process

The fourth experiment was conducted to find the best medium for adsorption of eosin y. From the results shown in Fig.4, it is clear that R\% was very high with walnut, while the $C$. fluminea was very weak in removing eosin y. Both adsorbents show that $\mathrm{R} \%$ was higher in the acidic medium than in the alkaline medium and that can be explain by the fact that cationic dye will be adsorbed better in the acidic medium. The results of this study was similar to the results of $(19,20)$.

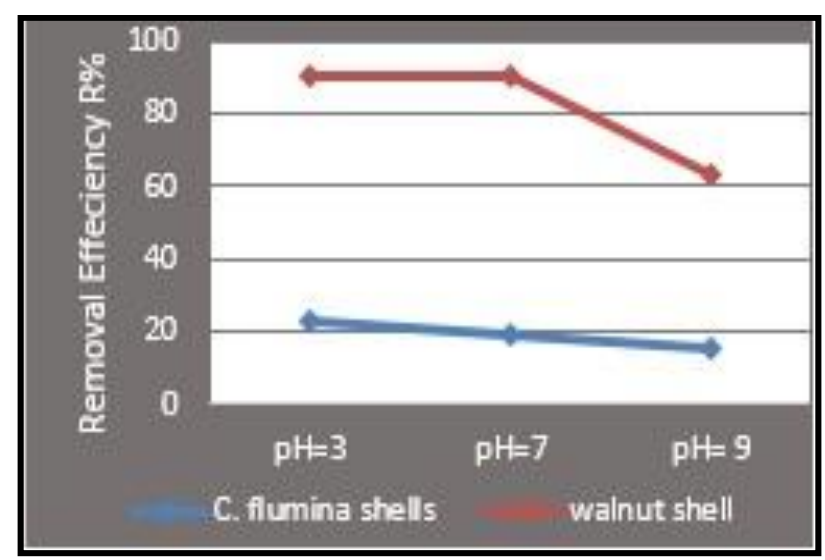

Figure 4. The effects of the solution $\mathrm{pH}$ value on the adsorption process

Throughout the whole study, the walnut shell was more effective than the $C$. fluminea in removing of eosin y, so in the fifth experiment, the effect of the particles size on the adsorption process was examined. Two types were used, fine powder and granular particles. The results shown in Fig. 5 illustrate that the fine powder was the best for adsorption. This can be explained by the fact that for the same weight used the fine powder provide much more surface area for adsorption than granular particles. 


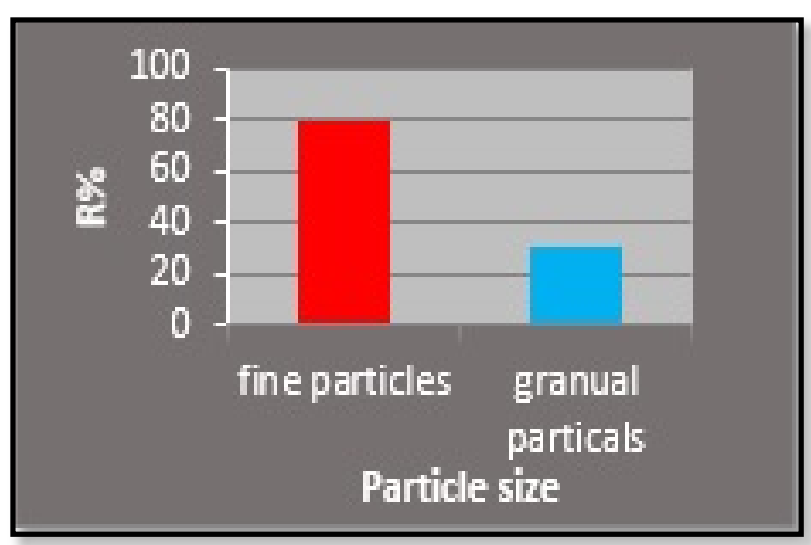

Figure 5. The effects of the particles size on the adsorption process

\section{Conclusion:}

Throughout this study we found that the nut shell is a very good candidate to use as adsorbent to remove eosin y from aqueous solutions, while the C. flumina was less effective in removing the dye.

\section{Conflicts of Interest: None.}

\section{References:}

1. Cheremisisnoff, N P. HandBook of water and waste water treatment technologies. ButterworthHeinmann, Boston, .2002. 654p.

2. Elhami, S, Abrishamkar M, Esmaeilzadeh L. Preparation and characterization of diethylentriamine-montmorillonite and its application for removal of Eosin $\mathrm{Y}$ dye: optimization, Kinetic and Isotherm Studies. J. SCI. IND. RES., 2013;72:461-66.

3. Agalya, A, Palanisamy P N, Sivakumar P. Kinetics equilibrium studies on removal of ionic dyes using a noval non- conventional activated carbon. I. J. Chem. Res., 2012; 3 (1) : 62-68.

4. Ansari R, Mosayebzadeh, Z. Removal of Eosin Y, an anionic dye, from aqueous solutions using conducting electroactive polymers. IPJ., 2010; 19(7) :541-551.

5. De Rigo D, Enescu, CM, Durrant TH, Tinner W, Caudullo G. Juglans regia in Europe: distribution, habitat, usage and threats. In: San-Miguel-Ayans, J., De Rigo, D., Caudullo, G., Durrant, T. and mauri, A. editors. European Atlas of Forest Tree Species. Publ. off Eu. Luxambourg, 2016; pp.

6. Oliveira I, Sousa A, Ferreira I C F R , Bento A , Esterinho L, Perreira J A. Total phenols, antioxidant potential and antimicrobial activity of walnut (Juglans regia L.) green husks. Food chem. Toxicol.2008; 46: 2326-2331.
7. Minhhin D. Carbicula fluminea. Delivering Alien Invasive Species DAISIE. January, 2008; pp.: 1-3.

8. Sousa R, Antunes C, Guilhermino L. Ecology of the invasive Asian clam Carbicula fluminea(Muller, 1774) in aquatic ecosystems: an overview. Ann. Limnol. Int. J. Lim.,2008;44( 2): 85-94.

9. Zhang F, Shi F, Ma W, Gao F, Jiao Y, Li H, et al..Controlling adsorption structure of Eosin Y dye on nanocrystalline Tio2 films for improved photovoltaic performances. J. Phys. Chem.C.2013; 117(28):14659-14666.

10. Agalya A, Palanisamy P N, Sivakumar P. Kinetics, equilibrium studies on removal of ionic dye using a noval non-conventional activated carbon. I. J. Chem. Res., 2012; 3(1):62-68.

11. Nandhakumar, V, Amudha B, Roopa V. Adsorption of Eosin dyes onto activated carbon prepared from wood of Adina cardifola hook- A kinetic and isotherm study. IJRCE,2015;5 (4):1-7.

12. Salman J M, Amrin A R, Hassan F M, Jouda S A. Removal of congo red dye from aqueous solution by using natural materials. Mesop. Environ. J., 2015;1(3): 82-85.

13. Salman J M, Abdal-Hussein N A, Al Muttairi A $\mathrm{K}$. Removing the methylene blue dye from aqueous solutions by low cost materials. International Journal of Advanced Research, 2015;3(4):523-530.

14. Hossain A, Rayhan A B M S, Raihan M J, Nargis A, Islami I M I, Habib A, et al. Kinatic of degradation of eosin $y$ by one of the advanced oxidation processes (AOPs)- Fentons process. Am. J. Analyt. Chem. 2016; 7:863-879.

15. Salh D M, Aziz B K, Faraidoon K. Adsorption of crystal violet on walnut shell from aqueous soltion. IJBAS-IJENS, 2015;15(4):4-8.

16. Salman J M, Al-Muttarri A K, Mustafa S A. Biosorption of Sifranin-O dye from aqueous solutions by using the shells of Carbicula flumina. Mesopo. Environ. J.2016;3(3): 25-29.

17. Tango R, Dai, C, Li C, Liu W, Gao S, Wang C. Removal of methylene blue from aqueous solution using agricultural residue of walnut shell: equilibrium, kinetic, and thermodynamic studies. Hindawi, J. Chem., 2017; doi.8404965.

18. Kant R. Adsorption of dye eosine from an aqueous solution on two different samples of activated carbon by static batch method. JWRP. 2012;4:93-94.

19. Bello O S, Olusegun O A, Njoku V O. Fly ash: an alternative to powdered activated carbon for the removal of eosine dye from aqueous solutions.Bull. Chem. Soc. Ethiop,2013;27(2): 191-204.

20. Mohammed A B,mranAR, Baiee M A, Salman J M. Biosorptionof Safranin-O From Aqueous Solution BY Nile Rose Plant (Eichhornia crassipes) .Baghdad Science Journal , 2018; 15(1):26-30. 


\section{دراسة مقارنة كفاعة مادتين مدمصه لإزله صبغة Eosin من المحاليل المائية}

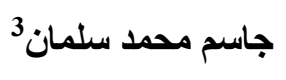

سما احمد مصطفى

1 مركز البحوث و الدراسات البيئية، جامعة بابل، بابل، العراق.

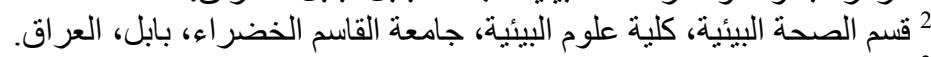

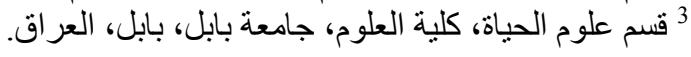

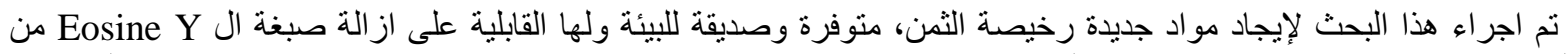

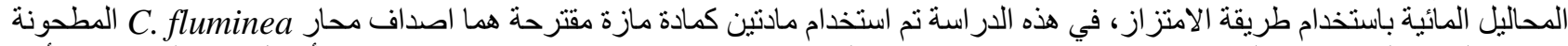

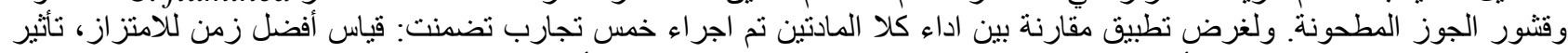

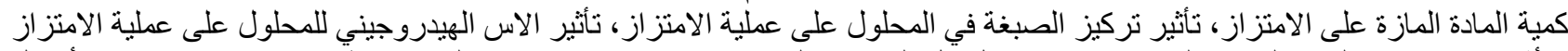

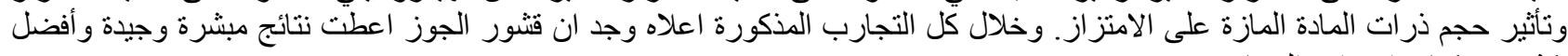
بكثير من كفاءة اصداف المحار. الكلمات المفتاحية: ادصاص، تلوث، صبغة Eosin Y، اصداف المحار، قثشور الجوز. 